\title{
PERBEDAAN PERSEPSI KETERTARIKAN INTERPERSONAL SISWA PADA GURU SEKOLAH DASAR BERDASARKAN UKURAN TUBUH
}

\author{
Gumgum Gumelar*
}

*Program Studi Psikologi, Universitas Negeri Jakarta

**Program Studi Psikologi, Universitas Negeri Jakarta

\author{
Cintya Guswiananda Nugraheni**
}

DOI: https://doi.org/10.21009/JPPP.041.06

\begin{abstract}
Alamat Korespondensi:
ggumelar@unj.ac.id
\end{abstract}

\begin{abstract}
This study aims to determine whether there is a difference in perceptions of interpersonal attractiveness of students in primary school teachers in Pondok Kelapa East Jakarta based on body size. This research uses quantitative approach with pre-experimental research method and quota sampling technique and questionnaire as data. This experiment was designed with digital manipulation of male and female teacher body size images as a stimulus variation, which then compares between variations and selected using the guttman scale with option 1 or 2. Then in rating with likert scale to know the level of interest. Subject of this study there are 155 people with age 18-12 years. The result of statistical analysis that yield is $F=28,284, p=0,000<0,05$ (significant). The results showed a significant difference perceptions of interpersonal interest of students in elementary school teachers according to body size.
\end{abstract}

Keywords

body size, interpersonal attractiveness

\section{Pendahuluan}

Pendidikan merupakan suatu hal yang penting karena dengan adanya pendidikan, manusia mendapatkan pengetahuan-pengetahuan baru yang dapat membuat kehidupannya menjadi lebih baik dan meningkatkan kualitasnya. Pendidikan menurut Sir Godfrey Thomson (dalam Yufiarti \& Wahyuni, 2013) adalah pengaruh lingkungan atas individu untuk menghasilkan perubahan-perubahan yang tetap (permanen) di dalam kebiasaankebiasaan tingkah lakunya, pikiran dan sikapnya. Sedangkan menurut Prof. Dr. M J Langeveld (dalam Yufiarti \& Wahyuni, 2013) pendidikan adalah setiap usaha, pengaruh, perlindungan dan bantuan yang diberikan kepada anak tertuju pada pendewasaan anak atau lebih tepat membantu anak agar cukup cakap melaksanakan tugas hidupnya sendiri. Pengaruh itu datangnya dari orang dewasa dan ditunjukan pada orang yang belum dewasa.

Pendidikan di Indonesia masih cukup tertinggal dari negara-negara berkembang maupun negara maju lainnya di seluruh dunia. Oleh karena itu untuk meningkatkan pendidikan Indonesia di butuhkan bantuan peran tenaga pendidik yang profesional yaitu Guru. Pengertian Guru dalam Undang-Undang Republik Indonesia Nomor 14 Tahun 2005 Tentang Guru dan Dosen dalam Bab I Pasal 1 yaitu "Guru adalah pendidik profesional dengan tugas utama mendidik, mengajar, membimbing, mengarahkan, melatih, menilai, dan mengevaluasi peserta didik pada pendidikan anak usia dini jalur pendidikan formal, pendidikan dasar, dan pendidikan menengah". 
Dalam peningkatan kualitas pendidikan di Indonesia, penting bagi guru untuk memiliki hubungan baik dengan peserta didiknya. Secara psikologis, langkah utama yang menjadi awal dari terciptanya hubungan dengan orang lain selalu sama, yaitu dengan adanya ketertarikan interpersonal, tepatnya ada keinginan untuk berdekatan dengan seseorang (Miller \& Perlman, 2009). Ketertarikan interpersonal antara siswa dengan guru dapat mempengaruhi proses belajar siswa secara positif, sesuai dengan pendapat Baron dan Byrne (dalam Rakhmat, 1998) yang menyebutkan bahwa siswa akan lebih bahagia ketika belajar pada suasana yang penuh persahabatan, mereka juga akan lebih bersemangat dalam belajar.

Sebagai tenaga pendidik, guru menentukan keberhasilan suatu pendidikan oleh karena itu guru harus memiliki kompetensi dan tanggung jawab dalam proses pendidikan. Kompetensi guru adalah kecakapan, kemampuan dan keterampilan yang dimiliki oleh seseorang yang bertugas mendidiksiswa agar mempunyai kepribadian yang luhur dan mulia sebagaimana tujuan dari pendidikan (Trianto, 2006). Menurut Cherepanova (2002) (dalam Mynbayeva \& Yessenova, 2016) kompetensi pendagogik memiliki dua struktur komponen yaitu komponen inti yang terdiri dari konsep diri, gambaran diri, kharisma, dan kompetensi profesionalitas serta komponen eksternal yang terdiri dari visual image, perilaku verbal, perilaku non-verbal, dan gambaran informasi.

Dalam menentukan apakah guru tersebut berkompeten atau tidak dalam mengajar membutuhkan waktu karena melalui proses panjang yang dilihat dari kemampuan guru tersebut dalam menerapkan segala pengetahuannya kepada peserta didik dan kecakapan guru tersebut dalam proses belajar mengajarnya serta serangkaian tes kompetensi. Oleh karena itu peneliti tertarik untuk membahas gambaran guru ideal dilihat dari salah satu komponen eksternal image yaitu visual image. Peneliti akan membahas dari segi fisik, jadi gambaran guru ideal dilihat dari penampilan fisiknya yaitu dari ukuran tubuh sesuai dengan persepsi siswa yang melihat pertama kalinya karena tidak membutuhkan waktu yang lama.

Persepsi adalah proses organisme menginterpretasikan dan mengorganisir sensasi untuk menghasilkan suatu pengalaman yang penuh arti (Yufiarti \& Gumelar, 2013). Sebagai peserta didik, siswa memiliki persepsinya masing-masing mengenai guru yang dianggapnya ideal baik secara kompetensi inti maupun eksternal imagenya. Persepsi yang ditimbulkan oleh siswa dipengaruhi oleh penampilan atau daya tarik fisik (physical attractiveness) yang ada pada guru. DeGenova(2008) mengemukakan bahwa elemen terpenting dari attraction atau daya tarik adalah physical attractiveness atau daya tarik fisik. Evans (2008) physical attractiveness ditentukan oleh bentuk tubuh (body attractiveness), wajah (facial attractiveness), suara (voice attractiveness) dan janggut. Peneliti hanya berfokus pada body attractiveness-nya saja karena secara visual yang paling menonjol dan terlihat pada bentuk tubuh adalah dari ukuran tubuhnya.

Hasil preliminary study oleh peneliti menunjukan bahwa siswa lebih tertarik untuk menjalin hubungan interpersonal dengan guru apabila guru tersebut memiliki fisik yang menarik karena siswa beranggapan bahwa guru yang menarik itu baik dan siswa akan lebih semangat belajar ketika ia memiliki hubungan dekat dengan guru tersebut serta siswa memiliki persepsi yang berbeda-beda ketika ditunjukan beberapa variasi ukuran tubuh guru. Oleh karena itu penelitian ini bertujuan untuk mengetahui "Perbedaan Persepsi Ketertarikan Interpersonal Siswa pada Guru Sekolah Dasar di Kelurahan Pondok Kelapa Jakarta Timur Berdasarkan Ukuran Tubuh" karena penampilan guru terutama ukuran tubuh secara keseluruhan adalah eksternal image yang pertama kali dilihat oleh siswa yang dapat menimbulkan persepsi bagi masing-masing siswa dan termasuk faktor ketertarikan interpersonal yang pastinya akan mempengaruhi proses belajar mengajar siswa.

Dalam sudut pandang psikologi sosial, ketertarikan interpersonal menunjukan bahwa atraksi dalam interaksi sosial memengaruhi persepsi mengenai daya tarik fisik dan berkaitan dengan terjalinnya hubungan antar manusia yang dapat terjadi dimanapun dan dalam situasi apapun (Tiolina, 2012). Langkah pertama terjadinya suatu hubungan sosial karena adanya interpersonal attraction atau ketertarikan interpersonal (Brehm, Miller, Perlman, \& Champbell, 2002 dalam Tiolina, 2012).

Ketertarikan interpersonal menurut Baron dan Byrne (2003) adalah sikap ketertarikan seseorang 
terhadap orang lain meliputi evaluasi sepanjang suatu dimensi yang berkisar dari sangat suka hingga sangat tidak suka. Feldman (2011), berpendapat bahwa ketertarikan interpersonal merupakan perasaan positif terhadap orang lain yaitu menyukai dan mencintai. Ketertarikan interpersonal adalah rasa suka terhadap orang lain, sikap positif, dan daya tarik seseorang (Rakhmat, 2009 dalam Anggraeni, 2015). Menurut Michener dan Delamater (1999), ketertarikan interpersonal merupakan tingkah laku positif yang ditunjukkan oleh seseorang dalam mendekati orang lain. Kemenarikan atau attraction dari seseorang paling dilihat melalui tampilan fisiknya karena fisik merupakan hal yang pertama kali dilihat oleh seseorang saat baru pertama kali bertemu dan dapat menimbulkan kesan pertama (first impression) baik positif maupun negatif bagi orang yang melihatnya. Orang cenderung membentuk kesan panjang lebar atas orang lain berdasarkan informasi terbatas (Seras, Freedman \& Peplau, 1992).

Tubuh merupakan salah satu komponen morfologi fisik yang menentukan ketertarikan Interpersonal. Dalam daya tarik fisik, tubuh merupakan bagian yang pertama kali dilihat. Evans (2008) menyatakan bahwa ada beberapa komponen morfologi fisik yang menentukan ketertarikaninterpersonal yaitu bentuk tubuh (body attractiveness), wajah (facial attractiveness), suara (voice attraactiveness), dan janggut. Dari beberapa komponen ketertarikan interpersonal tersebut, penelitian ini memfokuskan pada komponen tubuh atau body attractiveness. Apicella (2009) menyatakan bahwa body attractiveness merupakan bagian dari atribut fisik yang dapat dipersepsikan oleh panca indera. Bagian dari atribut fisik tersebut adalah bagian tubuh atau badan seseorang yang terlihat. Menurut Koscinki (2013), body attractiveness adalah penggabungan antara massa tubuh seseorang dan kelekukan tubuhnya (body curvaceousness) yang pada akhirnya menentukan kemenarikan fisik (physical attractiveness) seseorang. Komponen dalam body attractiveness pada laki-laki yaitu Body Mass Index (BMI), Waist-to-Chest Ratio (WCR), dan Waist-to-Hip Ratio (WHR) (Swami \& Tovee, 2005). Sedangkan komponen body attractiveness pada perempuan yaitu Body Mass Index (BMI),
Waist-to-Hip Ratio (WHR) dan ukuran payudara (breast size) (Koscinki, 2013).

Body Mass Index (BMI) adalah proporsi antara massa tubuh dalam satuan kilogram $(\mathrm{kg})$ dan kuadrat dari tinggi tubuh dalam satuan meter (m) (WHO, 2012). Massa tubuh seseorang ditentukan oleh jumlah jaringan lemak (Deurenberg dkk.; dalam Koscinski, 2013). Jadi semakin besar jaringan lemak dalam tubuh seseorang maka tubuh orang tersebut akan semakin besar sehingga nilai BMI akan semakin tinggi. Berdasarkan WHO (2012), BMI dapat di kategorikan ke dalam tiga kelompok ukuran berdasarkan nilai BMI yang dimiliki, yaitu 1) under weight (BMI < 18.5), 2) normal (BMI 18.5 - 25), 3) over weight (BMI > 25).

\section{Metode Penelitian}

Penelitian ini adalah penelitian eksperimen dengan menggunakan pendekatan kuantitatif dengan desain penelitian yaitu pre-eksperimen. Pada penelitian ini melakukan manipulasi dari variabel bebas (variasi ukuran tubuh) dengan menampilkan stimulus yang merupakan tiga kelompok ukuran tubuh berdasarkan nilai BMI dari WHO (2012), yaitu under weight, normal, dan over weight. Dimana tiga manipulasi tersebut akanditampilkan dengan membandingkan antara under weight dengan normal, under weight dengan over weight, dan normal dengan over weight menggunakan gambar ukuran tubuh lakilaki dan perempuan yang telah dimanipulasi.

Untuk variabel bebas di ukur menggunakan tiga jenis variasi manipulasi ukuran tubuh dari gambar perempuan dan laki-laki yang di bandingkan, kemudian dijawab dalam bentuk skala Guttman yang berupa pilihan 1 atau 2. Untuk variabel terikat di ukur menggunakan skala likert dari Sangat Suka(SS), Suka (S), Tidak Suka (TS), Sangat Tidak Suka (STS). Penelitian ini menggunakan desain penelitian within-subject design, yaitu membandingkan skor variabel terikat yang dimiliki oleh satu kelompok (Seniati $\mathrm{dkk}, 2015)$. Tujuan penelitian ini untuk melihat perberdaan persepsi ketertarikan interpersonal siswa berdasarkan ukuran tubuh guru dengan melihat seberapa banyak skor yang di dapat dalam tiap variasi ukuran tubuh. Oleh karena itu, penelitian ini hanya menggunakan satu kelompok eksperimen, yaitu One-group post test design. 
Tabel 1. Desain Penelitian

\begin{tabular}{lll}
\hline Manipulasi $(\mathrm{X})$ & $\rightarrow$ & Pengukuran $(\mathrm{O})$ \\
\hline
\end{tabular}

Dalam penelitian ini subjek yang dipakai adalah siswa yang berusia 10 sampai 12 tahun yang merupakan siswa sekolah dasar di Kelurahan Pondok Kelapa Jakarta Timur. Bersarkan teori psikologi perkembangan pada tahap pengamatan menurut Oswald Kroh, anak usia 10 sampai 12 tahun mengalami masa realisme kritis dimana anak mulai berpikir kritis dan mencapai tingkat berpikir abstrak. Penelitian ini menggunakan teknik sampel kuota dengan target 150 responden.

\section{Hasil Penelitian dan Diskusi}

Dalam penelitian ini jumlah responden sebanyak 155 responden tetapi jumlah data yang dapat dipakai sebanyak 136 responden. Responden yang berjenis kelamin laki-laki sebanyak 67 responden $(49,3 \%)$ sedangkan responden yang berjenis kelamin perempuan sebanyak 69 responden $(50,7 \%)$. Responden penelitian yang memiliki usia 10 tahun sebanyak 27 responden $(19,8 \%)$, usia 11 tahun sebanyak 81 responden $(59,6 \%)$, usia 12 tahun sebanyak 28 responden $(20,6 \%)$. Hasil data deskriptif dari variabel Ukuran Tubuh diperoleh dengan menggunakan alat ukur berdasarkan teori dan memiliki hasil distribusi deskriptif Ukuran Tubuh sebagai berikut:

Tabel 2. Distribusi Deskriptif Data Ukuran Tubuh

\begin{tabular}{ccccc}
\hline Variasi Ukuran & Mean & $\begin{array}{c}\text { Standar } \\
\text { Deviasi }\end{array}$ & $\begin{array}{c}\text { Nilai } \\
\text { terendah }\end{array}$ & $\begin{array}{c}\text { Nilai } \\
\text { tertinggi }\end{array}$ \\
\hline LK & 3,70 & 1,922 & 0 & 8 \\
\hline LN & 3,01 & 2,055 & 0 & 8 \\
\hline LG & 1,53 & 1,605 & 0 & 6 \\
\hline PK & 3,62 & 2,087 & 0 & 8 \\
\hline PN & 3,67 & 2,398 & 0 & 8 \\
\hline PG & 1,84 & 1,982 & 0 & 8 \\
\hline
\end{tabular}

Berdasarkan hasil uji statistika deskriptif dapat disimpulkan bahwa ukuran tubuh underweight laki-laki adalah item pertama yang paling disukai dengan mean sebesar 3,70 dan ukuran tubuh normal perempuan adalah item kedua yang paling banyak disukai dengan mean sebesar 3,67.

Berikut adalah signifikansi dari perbandingan skor antar variasi dengan menggunakan repeated measure ANOVA.

Tabel 3. Repeated Measure Sphericity Assumption

\begin{tabular}{ccc}
\hline Factor & F & Sig \\
\hline Ukuran Tubuh & 28,284 & 0,000 \\
\hline
\end{tabular}

Dari hasil analisis repeated measure dapat dikatakan bahwa hasil $\mathrm{F}$ hitung sebesar 28,284 dengan nilai $\mathrm{p}$ sebesar 0,000 . Jika nilai $\mathrm{p}$ dibandingkan dengan nilai $\alpha=0,005$ maka dapat di simpulkan $\mathrm{p}<\alpha$ yang artinya Hipotesis alternatif (Ha) dalam penelitian ini diterima sedangkan Hipotesis nol (Ho) pada penelitian ini ditolak. Jika dilihat menggunakan perbandingan antara $\mathrm{F}$ hitung dengan $\mathrm{F}$ tabel $(1: 135)$, hasilnya $\mathrm{F}$ tabel sebesar 3,91 yang dapat diartikan $\mathrm{F}$ hitung $>\mathrm{F}$ tabel. Kesimpulan dari data $\mathrm{F}$ hitung adalah Hipotesis alternatif (Ha) diterima dan Hipotesis nol (Ho) ditolak, dengan demikian terdapat perbedaan yang signifikan pada persepsi ketertarikan interpersonal siswa pada guru berdasarkan ukuran tubuh. 
Gumgum Gumelar

Cintya Guswiananda Nugraheni

\section{Kesimpulan}

Berdasarkan hasil analisis statistika dalam penelitian ini maka dapat disimpulkan bahwa terdapat perbedaan yang signifikan dari persepsi ketertarikan interpersonal siswa pada guru sekolah dasar di Kelurahan Pondok Kelapa Jakarta Timur berdasarkan ukuran tubuh. Hal tersebut dikarenakan stimulus variasi ukuran tubuh dapat memunculkan persepsi ketertarikan interpersonal yang berbeda-beda pada siswa.

\section{Daftar Pustaka}

Anggraeni, P. (2015). Hubungan antara Persepsi terhadap Tugas Akademik dan Atraksi Interpersonal Siswa terhadap Guru dengan Regulasi Diri Siswa Program Olimpiade Sains Nasional (OSN) SMA Negeri 10 Samarinda. eJournal Psikologi, 3 (2), 504516.

Baron, R. A., \& Byrne, D. (2003). Social Psychology, 10th ed. Boston: Ally and Bacon.

Degenova, M. K. (2008). Intimate Relationships, Mariage \& Families. United States: The McGraw-Hill Companies.

Evans, S. (2008) The Male Voice: an Evolutionary Perspective. Newcastle: Nortumbria press.

Feldman, R. S. (2011). Understanding Psychology, 10th ed. New York: McGraw-Hill.
Perbedaan Persepsi Ketertarikan Interpersonal Siswa pada Guru Sekolah Dasar Berdasarkan Ukuran Tubuh

Koscinski, K. (2013). Attractiveness of Women's Body: Body Mass Index, Waist-to-Hip Ratio, and Their Relative Importance. Behavioralecology. doi: 10.1093/beheco/ art016.

Miller, R. \& Perlman, D. (2009). Intimate Relationships 5th ed. New York: McGraw-Hill.

Swami, V \& Tovee, M. J. (2007). The Relative Contribution of Profile Body Shape and Weight to Judgements of Women's Physical Attractiveness in Britain and Malaysia. Elsevier, 4, 391-396. doi: 10. 1016/j.bodyim.2007.07.002.

Tiolina, S. (2012). Pengaruh Nada Suara LakiLaki terhadap Persepsi Attractiveness Perempuan. Depok: Universitas Indonesia.

Trianto. (2006). Tinjauan Yuridis Hak serta Kewajiban Pendidik Menurut UU Guru dan Dosen. Jakarta: Prestasi Pustaka.

Yufiarti, \& Wahyuni, L. D. (2013). Pengantar Ilmu Pendidikan. Jakarta: Fakultas Ilmu Pendidikan Universitas Negeri Jakarta.

Yufiarti., \& Gumelar, G. (2013). Sejarah dan Dasar-Dasar Psikologi. Jakarta: Universitas Negeri Jakarta.

Zulkifli. (1987). Psikologi Perkembangan. Bandung: Remadja Karya CV. 